\title{
Ten steps to effective teaching as a non-physician educator
}

\section{Patty McNally*}

Medical Education, Stritch School of Medicine, Loyola University Chicago, Maywood, IL, USA

*Correspondence: pmcnally@lumc.edu

With the competing pressures facing medical school faculty, teaching is no longer considered a top priority. For many reasons, both internal and external, patient care and research activities receive more recognition and financial support than teaching. Most physicians believe they teach well and are frequently correct despite their lack of formal training on the art and science of medical education. Too often this is due primarily to time constraints and a perceived lack of relevance.

As a non-physician medical educator with a terminal degree in Adult Education, there were many things I needed to learn to appropriately develop curricula that would attract a busy physician... who was not exactly clear if they needed anything I had to teach!

The literature review indicated that most physicians receive little training for their teaching roles. Irby says that many (physicians) develop teaching behaviors based on a combination of their own experiences and general conceptions of teaching derived from experience and observation. In a study that rank ordered 30 basic pedagogical principles that could enhance teaching effectiveness, clinical teachers, and non-clinician medical educators had a clear lack of congruence in their ratings of these principles. They did, however, agree on five areas (McLeod et al., 2009):

1. need for goals and objectives

2. emphasis on self-directed versus teacher-directed learning

3. importance of coaching

4. utility of understanding adult learning theory

5. idiosyncratic problem-solving (clinical decision making process)

With this data in hand, it was clear the physicians and I looked at the education of our learners from different perspectives. I had to find a way for them to value what I brought to the table as a non-physician educator. Now, in all fairness, most physicians were happy to have someone with formal adult education available to them as a resource. My faculty appointment is in the Neurology department and they were very enthusiastic when I suggested piloting a Resident as Teacher program. But, it was only after I followed what I have come to know as the 10 steps to becoming a nonphysician adult educator for physicians that I was embraced. As a well-known adult educator, Myles Horton said, "I made the road by walking it!” (Horton, 1991)

1. Educationese... who knew I was speaking it! During my first year as a medical school assistant dean I was told to drop the education language. This was a bit of a challenge in that I did not know what to drop and how to translate what I was saying to medical education language.

2. Partner with a physician - My credibility increased when I partnered with physicians during my first workshops and programs. My boss, a neurologist, was a great mentor and certainly helped with this.

3. Aliquots - Another shift to accommodate the schedules of busy physicians. I usually teach adult learners in $4 \mathrm{~h}$ blocks and knew that would not fit the schedule of a busy physician. I developed a $2 \mathrm{~h}$ Certificate in Academic Medicine that offered the same content twice a week. So, if a physician missed one session they could attend later the same week.

4. Drive-by learning - "Just tell me what I need to know." I wanted to build a community of learners with each program I developed. I usually do not lecture preferring learners to recognize their knowledge and share it with their colleagues in small group discussion. I wanted the knowledge they bring to the classroom to be valued and validated to be efficient and high yield for the physician.

5. Flexibility - The patient always comes first! So I am always ready for the beepers to go off and emergencies to happen. I also morph the content and the structure of any leaning environment to the needs of the physician.

6. Role modeling - I attempt to model the behavior of the content I am teaching.

7. Relevance - As with any learner, especially adults, the key to their commitment to learning is their understanding of why they are learning it!

8. Feedback - The only way any of us improve is with good feedback. I request feedback for every session or workshop by asking what three things they learned what I did well and what I could do better as a teacher or facilitator. Then we talk about it. Again, it models what should be happening in all teaching sessions, but, can be time prohibitive in a clinical setting.

9. Prior learning - Too often in the academic medical environment, the knowledge and experience the learner brings to the learning environment is neither valued or validated. This mistake can be changed by encouraging the exchange of information rather than downloading it to the learner. Participatory learning engages the learner and helps long term retention.

10.Environment - As an adult educator, providing a safe learning environment is critical and always a goal. When I first started in medical education, I was encouraged to follow a physician teaching students on the wards and see whether a safe learning environment could be achieved. Well, the challenges are real. However, it is incumbent on us as educators to develop a support system with a different framework to nurture our learners. The statistics indicate we are not doing very well in this area. Forty percent of female and $27 \%$ of male medical students and residents experienced pronounced symptoms of anxiety or depression, $30-50 \%$ of physicians report anxiety, sleeplessness, or depression and the suicide rate is twice that of the general population (Michelfelder, 2011). 
As I began this critical reflection on the transition to becoming a non-physician medical educator, I sat with an other trained adult educator and asked, What was our life like before when acute, benign, malignant, and bolis were used to describe medical conditions or the delivery of medication and not part of our everyday language to describe a test or a meeting or the volume of content delivered?

We decided we have acclimated to the environment and have learned to transform our educationese to the culture of medicine. We continue to learn from each other, after all no matter what the educational setting, the student comes first!

\section{ACKNOWLEDGMENTS}

Much appreciation to Beth Sonntag MA Ed for her ongoing collaboration on this project and for all the others over the years and to Linda Massari MA for her great skill at editing and encouragement. Thank you both!

\section{REFERENCES}

Horton, M. (1991). We Make the Road by Walking It. Philadelphia: Temple University Press.

McLeod, P., Steinert, Y., Chalk, C., Cruess, R., Cruess, S., Meterissian, S., Razack, S., and Snell, L. (2009). Which pedagogical principles should clinical teachers know? Teachers, and education experts disagree disagreements on important pedagogical principles. Med. Teach.31, e117-e124
Michelfelder, A. (2011). Physician Well Being Lecture. Maywood, IL: Loyola University Stritch School of Medicine.

Received: 07 December 2011; accepted: 14 January 2012; published online: 03 February 2012.

Citation: McNally P (2012) Ten steps to effective teaching as a non-physician educator. Front. Neur. 3:9. doi: 10.3389/ fneur.2012.00009

This article was submitted to Frontiers in Neurology Education, a specialty of Frontiers in Neurology.

Copyright (c) 2012 McNally. This is an open-access article distributed under the terms of the Creative Commons Attribution Non Commercial License, which permits non-commercial use, distribution, and reproduction in other forums, provided the original authors and source are credited. 